\title{
Development of a New Genetic Model for Absence Epilepsy: Spike-Wave Seizures in C3H/He and Backcross Mice
}

\author{
Wayne N. Frankel, ${ }^{1}$ Barbara Beyer, ${ }^{1}$ Christina R. Maxwell, ${ }^{2}$ Stephanie Pretel, ${ }^{1}$ Verity A. Letts, ${ }^{1}$ and Steven J. Siegel ${ }^{2}$ \\ ${ }^{1}$ The Jackson Laboratory, Bar Harbor, Maine 04609, and ${ }^{2}$ Division of Neuropsychiatry, University of Pennsylvania, Philadelphia, Pennsylvania 19104
}

To characterize the genetic basis of spike-wave discharges (SWDs) detected by electroencephalography (EEG) in C3H/He mice, substrains of $\mathrm{C} 3 \mathrm{H}$ mice were evaluated by EEG and sensitivity to ethosuximide. Crosses with the SWD-negative strain C57BL/6J were performed to map the underlying gene(s). $\mathrm{C} 3 \mathrm{H} / \mathrm{He}$ substrains exhibited a modest incidence (average of 19 SWDs per hour) of 7-8 $\mathrm{Hz}$ SWDs when at rest, compared with the $\mathrm{C} 3 \mathrm{HeB} / \mathrm{Fe}$ subline (four SWDs per hour). In the mapping backcross, however, many mice showed a very high incidence (50-220 SWDs per hour) throughout the recording period. SWDs were first detected at 3.5 weeks of age, were associated with behavioral arrest, were suppressed by ethosuximide, and were strongest in the cerebral cortex and thalamus. The major $\mathrm{C} 3 \mathrm{H}$ determinant of SWDs, spkw1 (spike-wave 1), mapped to chromosome (Chr 9), and together with a C57BL/6J determinant on Chr 8, spkw2, accounted for more than one-half of the phenotypic variation in the backcross mice. The modest SWD incidence in $\mathrm{C} 3 \mathrm{H} / \mathrm{He}$ mice and the high incidence in backcrosses implies that SWD could be a confounding variable for other behaviors. Because $\mathrm{C} 3 \mathrm{H} / \mathrm{He}$ mice have no other brain abnormalities, they are an attractive alternative for studying idiopathic absence epilepsy.

Key words: absence epilepsy; spike-wave discharge; inbred strain; genetic; $\mathrm{C} 3 \mathrm{H}$; corticothalamic

\section{Introduction}

Absence (or petit-mal) epilepsy is characterized by a brief arrest of normal behavior associated with abnormal spike-wave discharges (SWDs) as seen by electroencephalogram (EEG). Absence epilepsy has a strong genetic component, but its genetic basis is not well understood. However, several mutant and inbred strains of rodents show SWDs. Genetic absence epilepsy rats from Strasbourg (GAERS) and WAG rats have polygenic SWDs, but the underlying genes are not known (Gauguier et al., 2004; Rudolf et al., 2004). Several mouse spontaneous mutations exhibit SWDs as monogenic phenotypes, and the genes for these mutations are known: "tottering" (Cacnala ${ }^{\text {tg }}$ ) (Fletcher et al., 1996), "lethargic" (Cacnb4 $\left.{ }^{\text {lh }}\right)$ (Burgess et al., 1997), "ducky" (Cacna2d2 ${ }^{\mathrm{du}}$ ) (Barclay et al., 2001), "stargazer," (Cacng2 $2^{\text {stg }}$ ) (Letts et al., 1998), "mocha” (Ap3d1 ${ }^{\mathrm{mh} 2 \mathrm{~J}}$ ) (Kantheti et al., 1998), "slow-wave epilepsy" (Slc9a1 ${ }^{\text {swe }}$ ) (Cox et al., 1997), and "coloboma" (Cm, Snap25) (Zhang et al., 2004). In addition, the Hcn 2 knock-out mouse (mutant $I_{\mathrm{h}}$ channel) also has SWDs (Ludwig et al., 2003). Interestingly, four of these mutations occur in subunits of the high-threshold voltage-dependent calcium channel (VDCC). Although the functional relationship between these and the T-type channels known to be involved in absence seizures is unknown, the relationship between tonic firing (associated with $\mathrm{P} / \mathrm{Q}$ type currents) and burst firing (T-type currents)

Received Dec. 7, 2004; revised Feb. 16, 2005; accepted Feb. 18, 2005.

This work was supported by National Institutes of Health Grants NS31348 (W.N.F.) and P50 MH 6404501 (S.J.S.). We thank Carolyne Dunbar for excellent animal care and Drs. Ken Johnson and Susan Ackerman for critical review of this manuscript.

Correspondence should be addressed to Wayne Frankel, The Jackson Laboratory, 600 Main Street, Bar Harbor, ME 04609. E-mail: wnf@jax.org.

DOI:10.1523/JNEUROSCI.0231-05.2005

Copyright $\odot 2005$ Society for Neuroscience $\quad$ 0270-6474/05/253452-07\$15.00/0 in the circuits has been suggested as a link (Kim et al., 2001; Song et al., 2004). However, all known mouse strains with SWDs also have severe motor abnormalities not typically associated with absence epilepsy in humans.

Common inbred mouse strains, such as C57BL/6 (B6), $\mathrm{BALB} / \mathrm{c}$, and $\mathrm{C} 3 \mathrm{H}$ are often used as wild type, but this does not mean that they are normal. Being inbred and subjected to many generations of selection, inbred strains often have phenotypic abnormalities, some of which may model human disease. Many mouse strains (including $\mathrm{C} 3 \mathrm{H}$ ) carry a mutation in the Pde6b gene that causes severe retinal generation (Pittler and Baehr, 1991); others (such as I/Ln) carry mutations such as piebald with defects in the development of the neural crest; these are just two of many examples (Bogue, 2003). In the field of epilepsy, several mouse strains (e.g., EL, SWXL-4, PL) exhibit tonic-clonic and generalized convulsions with routine handling (Rise et al., 1991; Frankel et al., 1994; Kitami et al., 2004). In some strains, it has been shown that convulsions are explained by the inheritance of susceptibility alleles from nonepileptic parental strains (Frankel et al., 1994). These seizure disorders are inherited as polygenic traits, with each mapped locus only accounting for a fraction of the phenotypic variance, resulting in slow progress in gene identification in such models.

Although inbred mouse strains have not been described as having absence epilepsy phenotypes per se, in the 1970s an electroencephalographic phenomenon known as a "brief spindle episode" (BSE) was described in a few strains (Ryan and Sharpless, 1979). Those researchers discussed the possibility that the BSEs emanated from thalamocortical circuits, as do SWDs, but stopped short of describing them as absence models. BSEs have since been mentioned in a few studies as an outcome of alcohol withdrawal in some mouse strains (Veatch and Becker, 2002). 
A

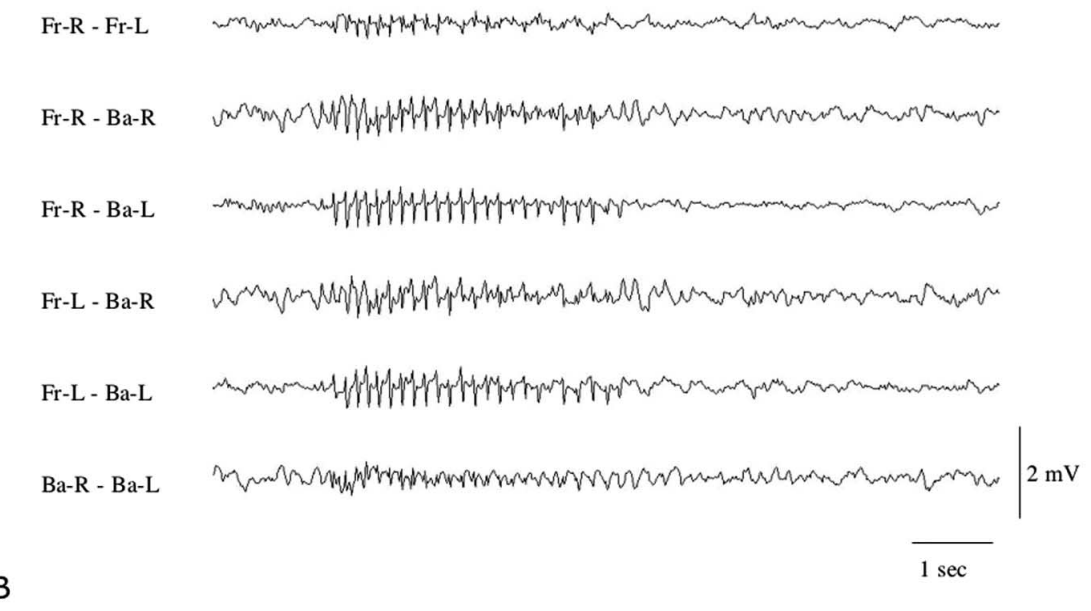

Fr-R - Fr-

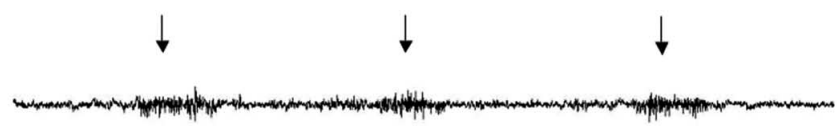

Fr-R - Ba-R

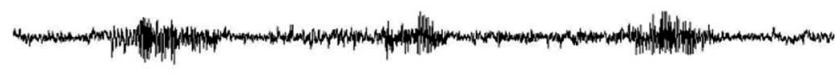

Fr-R - Ba-L

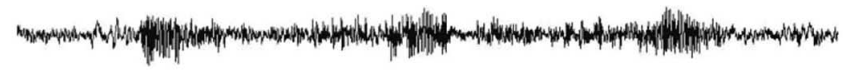

Fr-L - Ba-R

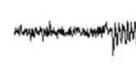

Fr-L - Ba-L

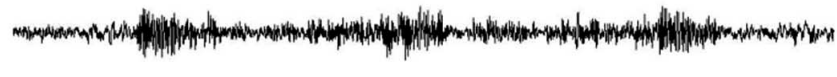

Ba-R - Ba-L

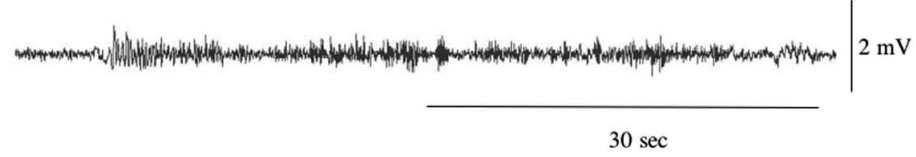

C

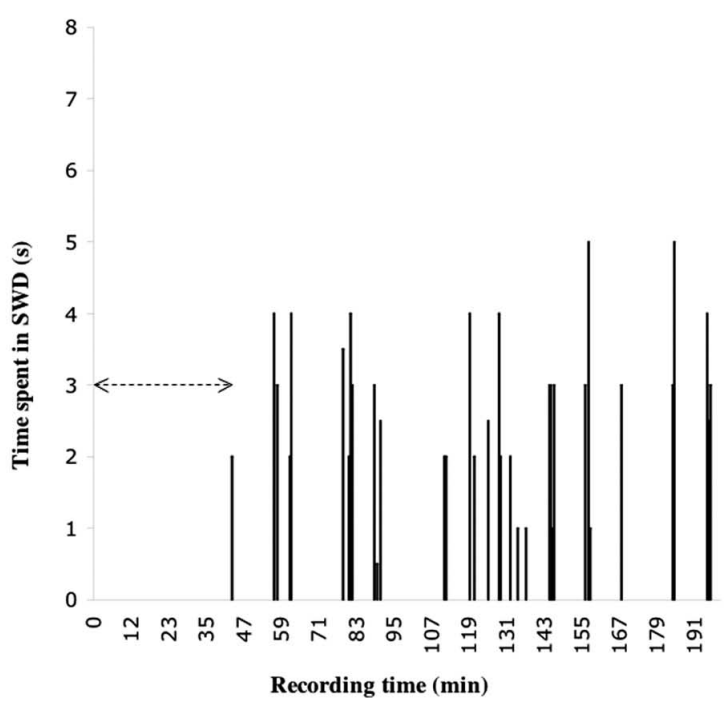

Figure 1. Representative SWDs of $\mathrm{C} 3 \mathrm{H} / \mathrm{HeJ}$ mice. $\boldsymbol{A}$, High resolution. $\boldsymbol{B}$, Low resolution. Arrows denote the SWD bursts described in Results. C, Onset and incidence of SWDs in a typical recording session (the double-headed arrow highlights a typical lag). Fr, Front; Ba, back; R, right; L, left.

Here we describe SWDs in a common mouse strain, $\mathrm{C} 3 \mathrm{H} / \mathrm{He}$, with no other brain abnormalities. We find that these SWDs have pharmacological and behavioral properties that model absence epilepsy, that they are modified by genetic background, and that a single major $\mathrm{C} 3 \mathrm{H}$-derived gene on chromosome 9 (Chr 9), in combination with a modifier gene on $\mathrm{Chr} 8$, accounts for the majority of SWD incidences.

\section{Materials and Methods}

Mice. All mice used in this study were obtained originally from The Jackson Laboratory (Bar Harbor, ME). C3H/HeJ mice used for depth recordings were housed at the University of Pennsylvania in an Association for Assessment of Laboratory Animal Care accredited facility with a $12 \mathrm{~h}$ light/dark cycle and ad libitum access to food and water; all other animals were housed in the Research Animal Facility at The Jackson Laboratory. All animal procedures were approved by the respective institutional animal care and use committee.

Surface or cortical EEG recordings. Mice that were between 3.5 and 10 weeks of age were tested for spontaneous SWD activity. Mice were anesthetized with tribromoethanol $(400 \mathrm{mg} / \mathrm{kg}$, i.p.) and placed in a stereotaxic holder fitted with a mouse incisor bar. Burr holes were drilled (posterior to bregma and $1 \mathrm{~mm}$ lateral to midline) on both sides of the skull. Either of two procedures was used to measure EEG activity. Initial studies were done using two Tefloncoated bipolar electrodes implanted at 0.1-0.5 $\mathrm{mm}$ below the dura. Screws were placed at the periphery of the skull to anchor the dental cap. Later studies (including genetic mapping) were done using four silver electrodes, soldered onto a microconnector, that were slid between the skull and the dura, two on each side of the cortex, and then a dental cap was applied. After the mice recovered from surgery and a $24 \mathrm{~h}$ resting period, EEG recordings were taken over a $3 \mathrm{~d}$ period, for a maximum of $3 \mathrm{~h}$ each day, using a Grass EEG Model 12 Neurodata Acquisition System and PolyviewPro software program (Grass Instruments, West Warwick, RI). The parameters for detecting SWDs have been described previously (Hosford et al., 1995).

Localized EEG recordings. To assess the brain regions involved in the generation of SWDs in $\mathrm{C} 3 \mathrm{H} / \mathrm{HeJ}$ mice, local bipolar electrodes were placed in the hippocampus [anteroposterior (AP), - 2.5; lateral (Lat), -3; depth, -4], thalamus (AP, -2.5 ; Lat, -1 ; depth, -4 ), and parietal cortex (AP, -2.5 ; Lat, -2 ; depth, -2 ) relative to bregma using the stereotaxic coordinate system. A total of 14 mice were used for this portion of the study. Among these, three mice had cortical bipolar recordings, four mice had hippocampal bipolar recordings, and seven had thalamic bipolar recordings. The surgical procedure was performed under isoflurane anesthesia. The mice were 10-11 weeks of age during recording. Two hours of resting EEG activity was recorded $7 \mathrm{~d}$ after electrode implantation using Spike 2 software (Cambridge Electronic Design, Cambridge, UK). Power spectral analysis with fast Fourier transforms was performed on the first five SWDs and five areas of interictal (non-SWD) activity for theta activity $(7.5-9 \mathrm{~Hz})$. A repeatedmeasures ANOVA was used to find main effects of SWDs and electrode placement. Significant interactions between SWDs and placement were 
followed by planned comparisons to determine regional changes in power with SWDs.

Genome scan, genetic analysis. For genetic mapping, genomic DNA from tail tips was prepared and sent to Kbiosciences (Hertfordshire, UK) for genome-wide single nucleotide polymorphism (SNP) analysis, using a marker approximately every 15 centimorgans in the genome. Additional simple sequence length polymorphism markers were typed as needed, in certain regions. Genotype data were tabulated, genetic marker maps were constructed, and genome scans were done for linkage of the trait SWDs per hour using MapManager QTX version b20 (www. mapmanager.org). Genome-wide significance thresholds for both main effect and pairwise scans were performed using the permutation test feature of MapManager, for 1000 permutations. Multivariate analysis was done using JMP software (SAS Institute, Cary, NC).

\section{Results}

\section{SWDs in $\mathrm{C} 3 \mathrm{H} / \mathrm{He}$ sublines}

In 2002, during EEG recordings done for the purpose of measuring auditory evoked potentials from several mouse strains, we noticed that $\mathrm{C} 3 \mathrm{H} / \mathrm{He}$ mice exhibited a high frequency of events that looked strikingly like the SWDs seen in stargazer mice (highamplitude, synchronous, bilateral spike-waves lasting for several seconds in the absence of auditory stimuli). To assess the brain activity of $\mathrm{C} 3 \mathrm{H} / \mathrm{HeJ}$ mice systematically, EEG recording was done using either depth, cortical (subdural), or epidural surface electrodes. In initial studies at the University of Pennsylvania, 80 male adult mice were implanted with unipolar intrahippocampal electrodes referenced to the ipsilateral frontal sinus; this electrode configuration reflects whole-brain EEG activity. SWDs with a frequency of $\sim 6-8 \mathrm{~Hz}$ and an amplitude between $\sim 800$ and $2300 \mu \mathrm{V}$ were noted in every mouse before and during auditory evoked potential tasks $7 \mathrm{~d}$ after electrode implantation. In follow-up studies at The Jackson Laboratory, both male and female adult $\mathrm{C} 3 \mathrm{H} / \mathrm{HeJ}$ mice were implanted with four unipolar surface electrodes, placed over each quadrant of the cerebral cortex, and differential recordings were made between poles. We observed high-amplitude, bilateral, synchronous SWDs frequently during a given recording session (Fig. $1 A$ ). Most $\mathrm{C} 3 \mathrm{H} /$ $\mathrm{HeJ}$ mice tested exhibited at least some SWD activity, defined as an episode lasting $>0.5 \mathrm{~s}$, greater than twice the amplitude of baseline, and observed in two or more channels. The burst frequency of the SWDs was $\sim 7-8 \mathrm{~Hz}$. The average duration was typically $2.5 \mathrm{~s}$, and the EEG appeared fairly normal before and after each episode. Although most of the study was done in adult mice, similar SWDs were observed in $\mathrm{C} 3 \mathrm{H} / \mathrm{HeJ}$ mice as young as 3.5 weeks of age (data not shown).

Using the less-invasive surface electrodes, the SWD episodes in adults appeared predominantly $\sim 30-40$ min after the beginning of recording, after the subject became less active from exploring the box and was settling down to rest; it was not yet asleep and still engaged in intermittent activities such as grooming. Once settled, however, the SWD bursts often appeared in clusters (Fig. $1 B, C$ ).

To determine whether other substrains of $\mathrm{C} 3 \mathrm{H}$ mice exhibit SWDs, we recorded from $\mathrm{C} 3 \mathrm{H} / \mathrm{HeOuJ}, \mathrm{C} 3 \mathrm{H} / \mathrm{HeSnJ}$, and $\mathrm{C} 3 \mathrm{HeB} /$ FeJ mice, the three major sublines that exist at The Jackson Laboratory. Whereas both the $\mathrm{HeOu}$ and $\mathrm{HeSn}$ sublines showed frequent SWDs in the same manner as the HeJ subline, including the burst frequency, incidence, and tendency to show episodes during wake-rest transition, significantly fewer SWDs ( $p=0.004 ; t$ test) were observed in mice from the eB/FeJ subline (see Fig. $3 A$ ). $\mathrm{F}_{1}$ hybrids between $\mathrm{HeJ}$ and $\mathrm{eB} / \mathrm{FeJ}$ showed the same low incidence of SWDs $(p=0.07)$ as $\mathrm{eB} / \mathrm{FeJ}$ (see Fig. $3 A$ ). Together, these results suggest that a recessive mutation(s) causing the higher

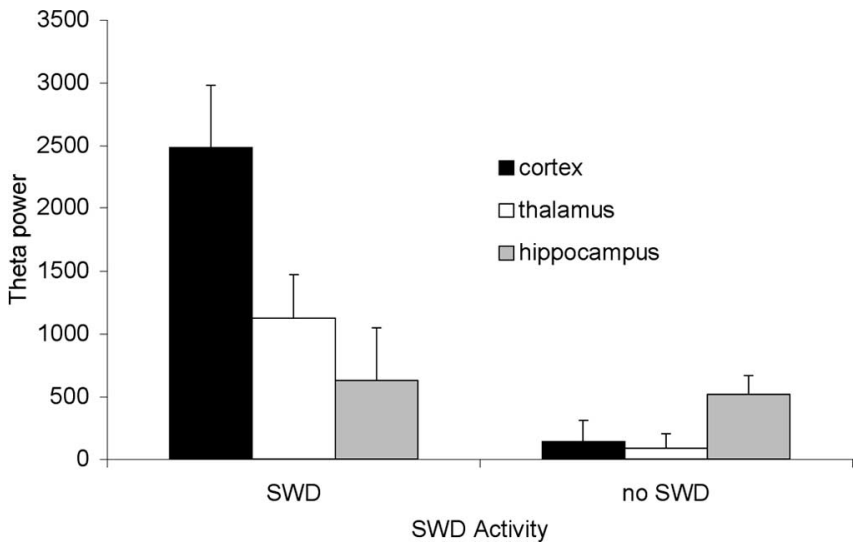

Figure 2. Localization of SWDs. SWD activity increases theta power in the cortex and thalamus but not in the hippocampus. Error bars represent SEM.

SWDs was not fixed in the $\mathrm{C} 3 \mathrm{HeB} / \mathrm{FeJ}$ subline when it diverged from the others and that additional variants associated with a low incidence of SWDs are shared among all $\mathrm{C} 3 \mathrm{H}$ strains.

To determine which brain region(s) were most involved in generating these SWDs, we implanted depth electrodes into the hippocampus (CA3), the thalamus, or the cortex and assessed which regions were associated with SWDs in the burst frequency range around 7.5-9 Hz, their typical range. Amplitude estimates during SWDs ranged from 300 to $800 \mu \mathrm{V}$, with non-SWD activity ranging from 75 to $400 \mu \mathrm{V}$ depending on region. The SWD duration ranged from 2.9 to $4.6 \pm 1.6 \mathrm{~s}$. Main effects of SWD $\left(F_{(1,10)}=16 ; p=0.002\right)$ and placement $\left(F_{(2,10)}=4.02 ; p=0.052\right)$ as well as a SWD by placement interaction $\left(F_{(2,10)}=4.18 ; p=\right.$ $0.047)$ indicate that the seizure intensity is regionally specific. Planned comparisons reveal increased power during SWDs in the cortex $\left(F_{(1,10)}=16.05 ; p=0.003\right)$ and thalamus $\left(F_{(1,10)}=6.25\right.$; $p=0.032)$ but not in the hippocampus $\left(F_{(1,10)}=0.04 ; p=0.841\right)$ (Fig. 2).

\section{Segregation analysis and trait locus mapping}

To determine the mode of inheritance, we first crossed $\mathrm{C} 3 \mathrm{H} / \mathrm{HeJ}$ mice to $\mathrm{B} 6$ mice and examined $\mathrm{F}_{1}$ hybrids: none exhibited SWDs, which is consistent with a recessive mode of inheritance (data not shown). We then crossed the $\mathrm{F}_{1}$ hybrids to $\mathrm{C} 3 \mathrm{H} / \mathrm{HeJ}$ mice and assessed SWDs in the resultant backcross, or $\mathrm{N}_{2}$ generation. A single-gene, Mendelian pattern of inheritance would have resulted in one-half of the $\mathrm{N}_{2}$ mice exhibiting SWDs and one-half appearing normal. Instead, we observed that almost all of the $\mathrm{N}_{2}$ mice exhibited SWDs, suggesting that that inheritance was nonMendelian (Fig. 3A). However, in the $\mathrm{N}_{2}$ population, the variation in SWD incidence was broad, with many mice exhibiting a much higher incidence and length of SWDs than any of the parental $\mathrm{C} 3 \mathrm{H} / \mathrm{HeJ}$ mice. For example, approximately one-half of the $\mathrm{N}_{2}$ mice had $>50$ SWDs per hour; some SWDs lasted for as long as $10-15 \mathrm{~s}$ (Fig. 3B). Interestingly, most backcross mice exhibited SWDs throughout their recording period and not just during restful periods.

Despite the fact that the inheritance was not simple, the variance in SWD rate among $\mathrm{N}_{2}$ mice encouraged us to attempt a genome scan to look for correlations between genotype and phenotype. More than 120 SNPs were genotyped across the genome in the majority of the 53 backcross mice, a robust linkage map was constructed using these markers, and marker regression was done to correlate genotype with the trait SWDs per hour. Strikingly, markers on centromeric Chr 9 showed a very high correla- 
A

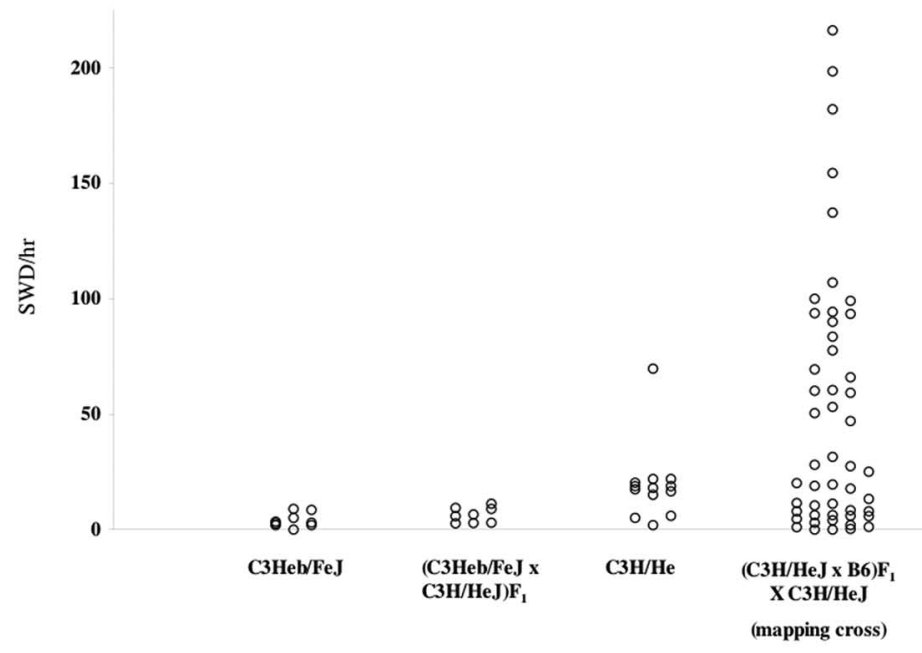

B

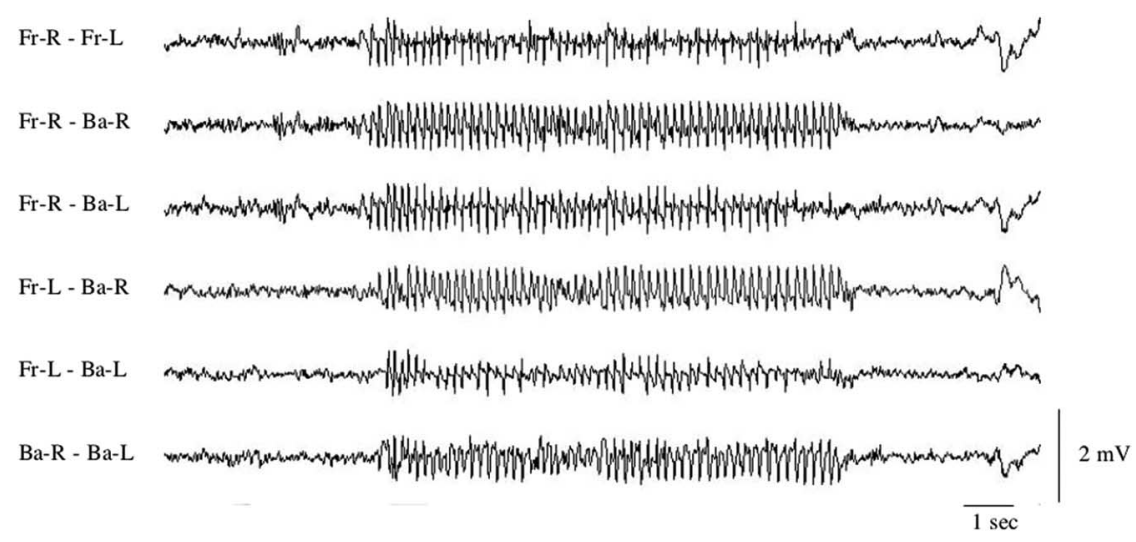

Figure 3. SWDs in an $\mathrm{F}_{1} \times \mathrm{C} 3 \mathrm{H} / \mathrm{HeJ}$ backcross $\left(\mathrm{N}_{2}\right)$ population. $A$, Distribution of SWDs per hour in $\mathrm{N}_{2}$ mice compared with $\mathrm{C} 3 \mathrm{H} / \mathrm{He}$ and $\mathrm{C} 3 \mathrm{HeB} / \mathrm{FeJ}$ sublines and $\left(\mathrm{C} 3 \mathrm{H} / \mathrm{He} \times(3 \mathrm{HeB} / \mathrm{FeJ}) \mathrm{F}_{1}\right.$ hybrids, showing higher incidence in the $\mathrm{N}_{2}$ mice. $\boldsymbol{B}$, Representative SWDs of $\mathrm{N}_{2}$ mice. Fr, Front; $\mathrm{Ba}$, back; $\mathrm{R}$, right; $\mathrm{L}$, left.

tion with the phenotype, surpassing the highly significant genome-wide threshold as estimated using permutation tests (Fig. 4A). This locus, which we have termed spkw1 (spike-wave 1 ), accounts for almost $40 \%$ of the total phenotypic variance in SWD rate in this backcross.

To begin to understand the non-Mendelian nature of the phenotype, we also performed a pairwise genome scan, testing whether loci act epistatically to affect SWDs. This test assesses whether pairs of loci, as opposed to one locus at a time, can interact with one another to account for the phenotype (Frankel and Schork, 1996). Using a permutation test to assess statistical significance (Churchill and Doerge, 1994), one pairwise interaction surpassed a significant $(p<0.05)$ genome-wide threshold, Chr 9 [National Center for Biotechnology Information (NCBI) refSNP accession number 3023202] by Chr 8 (NCBI refSNP accession number 3737220 or 3722665 ) (Fig. $4 B$ ). Furthermore, it was the $\mathrm{B} 6$ allele from $\mathrm{Chr} 8$, and not the $\mathrm{C} 3 \mathrm{H}$ allele, that was associated with high SWD incidence. Together, the Chr 9 singlelocus effect and its interaction with Chr 8 accounted for $52 \%$ of the total phenotypic variance, as assessed by multiple regression analysis (data not shown). No other significant locus associations or epistatic effects were detected in the backcross population.
SWDs in backcross mice have hallmarks of absence seizures

Two criteria of absence seizures in model organisms are as follows: (1) They should be accompanied by an arrest of normal behavior. (2) They should respond to antiabsence-specific drugs, such as ethosuximide (ETX). Because the parental $\mathrm{C} 3 \mathrm{H} / \mathrm{He}$ mice were not very active when SWDs occurred, and because the act of injecting ETX would interfere with the rest activity pattern, we could not conclusively assess these criteria in these mice. But because many $\mathrm{N}_{2}$ mice showed SWDs frequently and throughout the recording sessions, regardless of activity state, we were able to examine these important criteria. Indeed, the $\mathrm{N}_{2}$ mice ceased normal behavior and become still for the duration of the SWD, except for the occasional whisker twitch, after which the mice resumed normal behavior. We treated $\mathrm{N}_{2}$ mice showing various levels of SWDs with ETX (Fig. 5). Significantly fewer SWDs were observed in the 30 min period after ETX treatment than in the $30 \mathrm{~min}$ immediately preceding treatment ( $p=0.03$; repeated-measures ANOVA), after which the SWD incidence remained low or gradually resumed to previous levels (sample shown in Fig. $5 A$, all tests shown in Fig. 5B). Saline injection did not decrease the SWD incidence (Fig. 5B, stippled lines) Although some mice responded better to ETX than did others or recovered more quickly, the total number of SWDs observed in the mice $30 \mathrm{~min}$ after ETX treatment was very significantly lower than in saline-treated controls, compared with the incidence in the $30 \mathrm{~min}$ before treatment $\left(2 \times 2\right.$ contingency; $\chi^{2}=$ $44 ; p<0.0001)$. The onset of SWDs after treatment was also significantly delayed in ETX- vs saline-treated mice ( $t$ test, $p<0.02$; data not shown). Together, these results demonstrate that the SWDs of these mice are accompanied by the behavioral and pharmacological characteristics of absence seizures.

\section{Discussion}

In this study, we show that substrains and crosses involving $\mathrm{C} 3 \mathrm{H} / \mathrm{He}$ have a high incidence of SWDs, the hallmark electrophysiological characteristic of absence epilepsy. In humans, absence epilepsy has a strong genetic component, but progress in identification of the underlying genes has been slow, in part because it is often inherited as a genetically complex trait. Although a few genes for idiopathic generalized epilepsy in which some patients have absence seizures have been identified (Wallace et al., 2001), the best evidence for a genetic basis of absence epilepsy per se was finding mutations in the gene encoding $C A C N A 1 H$, a T-type low-threshold VDCC, in Northern Chinese children (Chen et al., 2003). This important finding was not a surprise based on the known role of T-type channels in SWDs and was presaged by studies of Cacnalg knock-out mice, which are resis- 
tant to chemically or genetically induced SWDs (Kim et al., 2001).

The manifestation of SWDs within $\mathrm{C} 3 \mathrm{H} / \mathrm{HeJ}$ adults was not typical for absence seizures, because they did not usually occur interspersed with periods of activity throughout an EEG recording session, but rather $30-40$ min into the session, when mice were beginning to nestle in their shavings for a rest. During this transition, bursts of frequent, highamplitude synchronous, bilateral SWDs were readily observed. However, when we recorded from $\mathrm{C} 3 \mathrm{H} / \mathrm{HeJ} \times(\mathrm{C} 3 \mathrm{H} / \mathrm{HeJ} \times$ C57BL/6J) $\mathrm{F}_{1}$ backcross $\left(\mathrm{N}_{2}\right)$ mice for segregation analysis and genetic mapping, we noticed that many exhibited SWDs very frequently, regardless of their activity state, suggesting that genetic modifier(s) from the C57BL/6J background relaxed the conditions under which SWDs are likely to occur. This broader manifestation of the phenotype made it possible for us to determine that these events have two of the hallmarks of absence seizures: behavioral arrest and pharmacological suppression by ethosuximide, which is selectively effective for absence epilepsy.

$\mathrm{C} 3 \mathrm{H} / \mathrm{He}$ mice represent an alternative to existing genetic models for studying absence epilepsy, because they do not have other major brain abnormalities, such as the movement disorders that impair the behavior of stargazer, tottering, and lethargic mutants, for example. The enhanced SWD phenotypes of many $\mathrm{C} 3 \mathrm{H} / \mathrm{He} \times \mathrm{B} 6$ backcross mice make it even more appealing. However, the B6-modified phenotype does not yet provide a useful working model, because backcross mice are not genetically uniform. Toward this end, we have begun to construct a congenic strain, containing mid-Chr 8 from C57BL/6J on a $\mathrm{C} 3 \mathrm{H} / \mathrm{He}$ strain background.

Most of the genetic effect on the incidence of SWDs in the backcross mice comes from spkw1, a C3H/He-derived allele on centromeric Chr 9. By itself, it accounts for almost $40 \%$ of the total phenotypic variance, and together with a C57BL/6J-derived modifier on Chr 8 , it accounts for $>50 \%$. Considering that there is some inherent procedural variance in measuring the EEG quantitatively in freely moving mice because of movement artifact, manual data review, or the occasional loose connection affecting the strength or integrity of the EEG signal, it is likely that the Chr 8 and Chr 9 effects account for most of the genetic variance (a parameter that cannot be measured directly in our study). That we were able to detect such strong effects at all in only 53 backcross mice also supports this model. However, a two-gene model cannot explain the entire effect, because no SWDs were seen in $\mathrm{F}_{1}$ mice, and yet almost all of the $\mathrm{N}_{2}$ mice (including $\mathrm{Chr}$ 9 heterozygotes) experience some level of SWDs; this suggests that there may be additional recessive alleles with small effects.

The $\mathrm{C} 3 \mathrm{H}$ inbred strain was derived in the 1920s from a cross of a Bagg albino female with a DBA male. $\mathrm{C} 3 \mathrm{H}$ is a very popular strain for research and is most well known for its high incidence of mammary tumors caused by an exogenous mouse mammary tumor virus. Like some other inbred strains, it also is homozygous for the retinal degeneration mutation, a very old mutation in the gene encoding PDE6B, causing severe visual impairment by young adulthood. The $\mathrm{C} 3 \mathrm{H} / \mathrm{He}$ substrain (He for Heston) arose in the 1940s. The substrains tested in this study were derived over the subsequent decade. We found that three of the four substrains showed a modest to high incidence of SWDs, but one, $\mathrm{C} 3 \mathrm{HeB} / \mathrm{FeJ}$, showed a very low incidence. This suggests that the parental $\mathrm{C} 3 \mathrm{H}$ strain already had a low-level predisposition to SWDs and that a new major mutation, likely $s p k w 1$, arose later but was not yet fixed in the germline until after 1948, when the $\mathrm{C} 3 \mathrm{HeB} / \mathrm{FeJ}$ substrain was derived. Considering that $\mathrm{C} 3 \mathrm{H} / \mathrm{He}$ is a popular strain, it is important to consider what effects these SWDs might have on behavioral studies. Although adult $\mathrm{C} 3 \mathrm{H} / \mathrm{He}$ mice are visually impaired and are therefore not usually given behavioral tests that rely on vision, one would expect to observe confounding effects on sleep and possibly eating or drinking behaviors attributable to this absence seizure phenotype. 
A

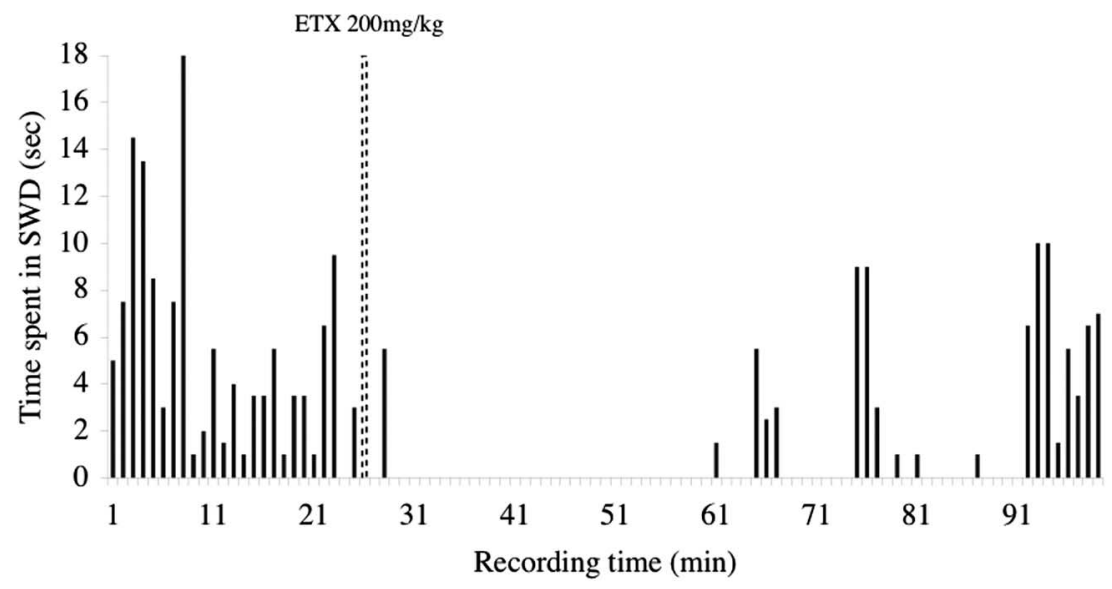

B

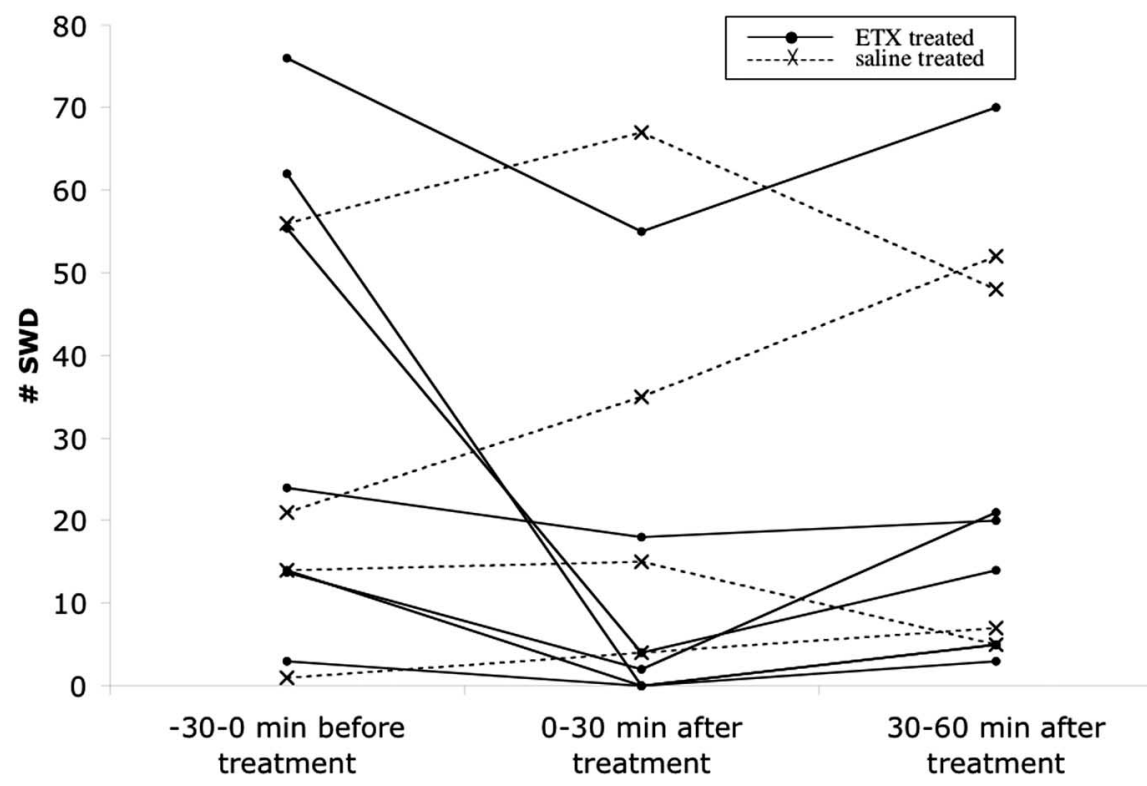

Figure 5. Ethosuximide suppresses SWDs in backcross mice. $A$, Sample plot of a recording session from a backcross mouse in which ETX ( $200 \mathrm{mg} / \mathrm{kg}$ ) reduced the number of SWDs. ETX was injected intraperitoneally $\sim 25$ min into the session. B, Summary of SWD incidence of six ETX-treated ( $\mathbf{O}$, solid line) and four saline-treated ( $\times$, dashed line) backcross mice in the $30 \mathrm{~min}$ before treatment, in the 30 min immediately after treatment, and in a subsequent 30 min period.

At present, the $95 \%$ confidence interval for the location of spkw1 on Chr 9 is quite broad $(\sim 30 \mathrm{Mb})$. We do note, however, that the centromeric third of this interval, where spkw1 most likely resides, contains only 29 genes, although none encode ion channels known to be involved in epilepsy. The gene encoding the ionotropic AMPA receptor Gria4 (also known as Glur-4), which is expressed in the cortex and in the thalamus, is located near the likelihood peak for $s p k w 1$. However, in this gene, no coding-sequence differences or gross expression differences were detected between $\mathrm{C} 3 \mathrm{H} / \mathrm{He}, \mathrm{C} 3 \mathrm{HeB} / \mathrm{FeJ}$, and $\mathrm{B} 6$ mouse strains (data not shown). Although we cannot exclude the possibility that a more subtle expression difference in Gria4 is responsible for the phenotype, it is more likely that the underlying gene will be a novel target for absence epilepsy. Another ion channel that maps to the so far broad critical interval for spkw1 is Kcnj5, also known as G-protein-activated inwardly rectifying $\mathrm{K}^{+}$channel
(GIRK4). GIRK4 is expressed in discrete regions of the brain, including certain cortical and thalamic nuclei. GIRK4 knockout mice have been generated, and they exhibit deficiencies in several behavioral tests; however, their EEG has not been reported, so it is unknown whether they exhibit SWDs. Similarly, however, we have detected no coding-sequence variants in Kcnj5 between the relevant mouse strains. To date, there are not many trait loci mapped for human absence epilepsy, and of those that are mapped, none reside on human chromosomes 11q or 19p, where the spkw1 homolog maps. However, of the two polygenic rat models for absence epilepsy, one (GAERS) had a suggestive association with a marker on rat $\mathrm{Chr} 8$, which is in the region orthologous to that in which $s p k w 1$ resides. It will be interesting to determine whether and how spkw1 is related to this minor locus from this popular rat model for epilepsy.

\section{References}

Barclay J, Balaguero N, Mione M, Ackerman SL, Letts VA, Brodbeck J, Canti C, Meir A, Page KM, Kusumi K, Perez-Reyes E, Lander ES, Frankel WN, Gardiner RM, Dolphin AC, Rees M (2001) Ducky mouse phenotype of epilepsy and ataxia is associated with mutations in the Cacna2d2 gene and decreased calcium channel current in cerebellar Purkinje cells. J Neurosci 21:6095-6104.

Bogue M (2003) Mouse Phenome Project: understanding human biology through mouse genetics and genomics. J Appl Physiol 95:1335-1337.

Burgess DL, Jones JM, Meisler MH, Noebels JL (1997) Mutation of the $\mathrm{Ca}^{2+}$ channel $\beta$ subunit gene $C c h b 4$ is associated with ataxia and seizures in the lethargic (lh) mouse. Cell 88:385-392.

Chen Y, Lu J, Pan H, Zhang Y, Wu H, Xu K, Liu X, Jiang Y, Bao X, Yao Z, Ding K, Lo WH, Qiang B, Chan P, Shen Y, Wu X (2003) Association between genetic variation of CACNA1H and childhood absence epilepsy. Ann Neurol 54:239-243.

Churchill GA, Doerge RW (1994) Empirical threshold values for quantitative trait mapping. Genetics 138:963-971.

Cox GA, Lutz CM, Yang CL, Biemesderfer D, Bronson RT, Fu A, Aronson PS, Noebels JL, Frankel WN (1997) Sodium/hydrogen exchanger gene defect in slow-wave epilepsy mutant mice. Cell 91:139-148.

Fletcher CF, Lutz CM, O'Sullivan TN, Shaughnessy Jr JD, Hawkes R, Frankel WN, Copeland NG, Jenkins NA (1996) Absence epilepsy in tottering mutant mice is associated with calcium channel defects. Cell 87:607-617.

Frankel WN, Schork NJ (1996) Who's afraid of epistasis? Nat Genet 14:371-373.

Frankel WN, Taylor BA, Noebels JL, Lutz CM (1994) Genetic epilepsy model derived from common inbred mouse strains. Genetics 138:481-489.

Gauguier D, van Luijtelaar G, Bihoreau MT, Wilder SP, Godfrey RF, Vossen J, Coenen A, Cox RD (2004) Chromosomal mapping of genetic loci controlling absence epilepsy phenotypes in the WAG/Rij rat. Epilepsia 4:908-915.

Hosford DA, Lin FH, Kraemer DL, Cao Z, Wang Y, Wilson Jr JR (1995) Neural network of structures in which $\mathrm{GABA}_{\mathrm{B}}$ receptors regulate absence seizures in the lethargic $(l h / l h)$ mouse model. J Neurosci 15:7367-7376. 
Kantheti P, Qiao X, Diaz ME, Peden AA, Meyer GE, Carskadon SL, Kapfhamer D, Sufalko D, Robinson MS, Noebels JL, Burmeister M (1998) Mutation in AP-3 delta in the mocha mouse links endosomal transport to storage deficiency in platelets, melanosomes, and synaptic vesicles. Neuron 21:111-122.

Kim D, Song I, Keum S, Lee T, Jeong MJ, Kim SS, McEnery MW, Shin HS (2001) Lack of the burst firing of thalamocortical relay neurons and resistance to absence seizures in mice lacking $\alpha(1 \mathrm{G}) \mathrm{T}$-type $\mathrm{Ca}^{2+}$ channels. Neuron 31:35-45.

Kitami T, Ernest S, Gallaugher L, Friedman L, Frankel WN, Nadeau JH (2004) Genetic and phenotypic analysis of seizure susceptibility in PL/J mice. Mamm Genome 15:698-703.

Letts VA, Felix R, Biddlecome GH, Arikkath J, Mahaffey CL, Valenzuela A, Bartlett II FS, Mori Y, Campbell KP, Frankel WN (1998) The mouse stargazer gene encodes a neuronal $\mathrm{Ca}^{2+}$ channel $\gamma$ subunit. Nat Genet 19:340-347.

Ludwig A, Budde T, Stieber J, Moosmang S, Wahl C, Holthoff K, Langebartels A, Wotjak C, Munsch T, Zong X, Feil S, Feil R, Lancel M, Chien KR, Konnerth A, Pape HC, Biel M, Hofmann F (2003) Absence epilepsy and sinus dysrhythmia in mice lacking the pacemaker channel HCN2. EMBO J 22:216-224.

Pittler SJ, Baehr W (1991) Identification of a nonsense mutation in the rod photoreceptor cGMP phosphodiesterase $\beta$-subunit gene of the rd mouse. Proc Natl Acad Sci USA 88:8322-8326.
Rise ML, Frankel WN, Coffin JM, Seyfried TN (1991) Genes for epilepsy mapped in the mouse. Science 253:669-673.

Rudolf G, Bihoreau MT, Godfrey RF, Wilder SP, Cox RD, Lathrop M, Marescaux C, Gauguier D (2004) Polygenic control of idiopathic generalized epilepsy phenotypes in the genetic absence rats from Strasbourg (GAERS). Epilepsia 4:301-308.

Ryan LJ, Sharpless SK (1979) Genetically determined spontaneous and pentylenetetrazol-induced brief spindle episodes in mice. Exp Neurol 66:493-508.

Song I, Kim D, Choi S, Sun M, Kim Y, Shin HS (2004) Role of the $\alpha 1 \mathrm{G}$ T-type calcium channel in spontaneous absence seizures in mutant mice. J Neurosci 24:5249-5257.

Veatch LM, Becker HC (2002) Electrographic and behavioral indices of ethanol withdrawal sensitization. Brain Res 946:272-282.

Wallace RH, Marini C, Petrou S, Harkin LA, Bowser DN, Panchal RG, Williams DA, Sutherland GR, Mulley JC, Scheffer IE, Berkovic SF (2001) Mutant $\mathrm{GABA}_{\mathrm{A}}$ receptor $\gamma 2$-subunit in childhood absence epilepsy and febrile seizures. Nat Genet 28:49-52.

Zhang Y, Vilaythong AP, Yoshor D, Noebels JL (2004) Elevated thalamic low-voltage-activated currents precede the onset of absence epilepsy in the SNAP25-deficient mouse mutant coloboma. J Neurosci 24: 5239-5248. 